\title{
Role of Dynamic Contrast Enhanced MRI in Characterization of Breast Lesions
}

\author{
Issar P, Issar SK
}

Department of Radiology, J.L.N. Hospital \& Research Centre, S.A.I.L., Bhilai, Chhattisgarh, India

\begin{abstract}
Purpose: To assess the role of Dynamic contrast enhanced magnetic resonance imaging in characterization of breast lesions and to differentiate benign from malignant lesions on the basis of their morphology and enhancement kinetics. Material and Methods: Sixty patients referred to the department of Radiodiagnosis for breast MRI over a period of twenty months were included. Dynamic contrast enhanced (DCE) Magnetic Resonance Imaging (MRI) was performed to differentiate breast lesions on the basis of morphology and enhancement kinetics. The lesions were classified accordingly into type I (progressive enhancement) Type II (plateau) and Type III (washout) kinetics. Morphology and curves of benign and malignant lesions were compared. Result: fifty one benign lesions were detected in 32 patients and 29 malignant lesions were seen in 22 patients, whereas six patients showed normal MRI. It was found that benign lesion were round or oval in shape with well circumscribed margin and showed homogenous contrast enhancement whereas malignant lesions were irregular with spiculated margin and showed heterogenous contrast enhancement. The distribution curve types of benign lesion were Type I (81.25\%-26cases), Type II (18.25\%-6cases). For malignant lesions Type I (4.54\%-1case), Type II (22.72\%5cases) and Type III (72.72\%-16cases). Conclusion: The shape of the time- signal intensity curve were an important criteria in differentiating benign from malignant lesions in dynamic breast MR imaging. A type III time curve is a strong indicator of malignancy and is independent of other criteria.
\end{abstract}

Keywords: Breast, Benign, Malignant, MRI, DCE

\section{Introduction}

Breast MRI has been increasingly used in clinical practice. It has played important roles in breast cancer management, including

Corrospondence to: Dr. Pratibha Issar, J.L.N. Hospital \& Research Centre, S.A.I.L., Bhilai, Qrt.No. 3B, S.P.A.Sector-9, Bhilai 490009 Chhattisgarh, India

Email Id: mareesh_23@yahoo.co.in staging of breast cancer, monitoring of response to neoadjuvant chemotherapy, evaluation of patients with metastatic axillary lymph nodes with unknown primary tumor, screening of breast cancer in women at high risk, and problem solving when findings at mammography and Ultrasonography are inconclusive. ${ }^{1,2}$

Dynamic contrast enhanced (DCE) MR imaging with adequate spatial and temporal 
resolution, facilitated assessment of both morphologic and enhancement kinetic features, as are described in the Standardized American college of Radiology (ACR) breast imaging reporting and Data system (BIRADS) MR Imaging Lexicon. New revisions of the MRI lexicon serve to further clarify breast MR imaging reporting, improve lesion diagnosis and management and facilitate patient care. $^{3,4}$

The goal of the study was to assess the role of Dynamic contrast enhanced magnetic resonance imaging in characterization of breast lesions and to differentiate benign from malignant lesions on the basis of their morphology and signal intensity curve.

\section{Material and Methods}

This is a prospective study of sixty consecutive patients (age distribution 24 to 75 years) from June 2012 to January 2014. Inclusion criteria for the study were presence of indeterminate masses on mammography and /or ultrasound, follow up of breast cancer, post-operative scar, nipple discharge and ulceration, breast infection, dense breast on X-Ray mammogram, screening tool for breast cancer in high risk females and in patient with metastatic axillary lymph node with unknown primary. Exclusion criteria were patient with normal X-Ray mammogram and ultrasound. All diagnosis was confirmed by FNAC/biopsy mostly with ultrasound guidance, wherever possible or required. Most of the MR examination was performed during the second phase of menstrual cycle (Days 7-14), except in cases of suspected malignancy. The indications for breast MRI are summarized in Table1.
Breast MR was done with eight channel double breast coil in prone position using Signa Excite 1.5 Tesla MRI machine GE Healthcare (advantage window 4.0 GE Healthcare). Subtraction images were obtained after subtraction of unenhanced images from contrast enhanced images. Time signal intensity curves (Kinetic curves) for abnormal finding were obtained by placing ROI (Region of interest) over required area. MIP (Maximum intensity projection) images were also obtained. The MR technique is summarized in Table 2.

Contrast material was injected I.V $(0.1 \mathrm{mmol} / \mathrm{Kg}$ of Gadiodiamide (Omniscan, GE healthcare) and followed by a $20 \mathrm{ml}$ saline flush at a rate of $2 \mathrm{ml} / \mathrm{sec}$, For dynamic study- unenhanced images were obtained follow by 6 series of enhanced images. Dynamic contrast images were reviewed at a workstation (Advantage Window 4.0 G.E.Healthcare). Equal matrixsize subtraction images of the unenhanced and contrast- enhanced images were used.Time signal intensity curves for abnormal findings were calculated from the dynamic study. All lesions were reported according to the BI- RADS lexicon for MRI on the basis of their morphologic features and kinetics of contrast enhancement.

\section{Data Analysis}

\section{Result}

Out of sixty cases, thirty eight cases were benign in nature which includes six normal cases whereas malignancy was detected in twenty two cases. Background parenchymal enhancement (BPE) of breast lesions were categorized on the basis of both amount and the degree of normal parenchyma 
Table 1: Indication for MRI and frequency of benign and malignant findings.

\begin{tabular}{|l|l|l|l|l|}
\hline \multicolumn{1}{|c|}{ Indications } & $\begin{array}{l}\text { Normal } \\
(\mathbf{6})\end{array}$ & $\begin{array}{l}\text { Benign } \\
(\mathbf{N = 3 2})\end{array}$ & $\begin{array}{l}\text { Malignant } \\
(\mathbf{N = 2 2})\end{array}$ & $\begin{array}{l}\text { Total } \\
(\mathbf{N = 1 5 )}\end{array}$ \\
\hline $\begin{array}{l}\text { Indeterminate mass on } \\
\text { mammography or ultrasound }\end{array}$ & - & 18 & 7 & 25 \\
\hline Evaluation of breast cancer & - & - & 7 & 7 \\
\hline Follow up of breast cancer & 1 & - & 2 & 3 \\
\hline Post-operative scar evaluation & 2 & 2 & 1 & 5 \\
\hline A Nipple discharge ulceration & - & 4 & 3 & 7 \\
\hline Breast infection & - & 2 & & 2 \\
\hline $\begin{array}{l}\text { Dense breast on } \\
\text { X-Ray mammogram }\end{array}$ & - & 5 & 1 & 6 \\
\hline $\begin{array}{l}\text { Screening tool for breast cancer } \\
\text { in high risk females }\end{array}$ & 2 & 1 & 1 & 4 \\
\hline $\begin{array}{l}\text { Patient with metastatic axillary } \\
\text { lymph node }\end{array}$ & 1 & - & - & 1 \\
\hline
\end{tabular}

Table 2: MRI Technique

\begin{tabular}{|l|l|l|l|l|l|l|l|}
\hline Sequence & TR & TE & $\begin{array}{l}\text { Flip } \\
\text { angle }\end{array}$ & $\begin{array}{l}\text { Slice } \\
\text { thickness }\end{array}$ & $\begin{array}{l}\text { Matrix } \\
\text { size }\end{array}$ & $\begin{array}{l}\text { FOV } \\
(\mathbf{m m})\end{array}$ & NEX \\
\hline Sag FSE T2 FS & 4160 & 89.9 & 90 & 5 & $256 \times 256$ & $20 \times 20$ & 4 \\
\hline Ax FSE T2 FS & 3240 & 85.8 & 90 & 5 & $320 \times 256$ & $36 \times 36$ & 2 \\
\hline Ax FSE T2 & 6060 & 1116.4 & 90 & 5 & $320 \times 256$ & $36 \times 36$ & 3 \\
\hline Ax FSE T1 & 540 & 14.8 & 90 & 5 & $320 \times 224$ & $36 \times 36$ & 3 \\
\hline Ax DWI B:500 & 1925 & 57.1 & 90 & 8 & $200 \times 160$ & $36 \times 36$ & 4 \\
\hline $\begin{array}{l}\text { Dynamic study } \\
\text { sequence }\end{array}$ & & & & & & & \\
\hline $\begin{array}{l}\text { Pre contrast Ax } \\
\text { Vibrant }\end{array}$ & 6.1 & 2.9 & 10 & 2.2 & $350 \times 224$ & $36 \times 36$ & .76 \\
\hline $\begin{array}{l}\text { Post contrast } \\
\text { Ax vibrant }\end{array}$ & 6.1 & 2.9 & 10 & 2.2 & $350 \times 224$ & $36 \times 36$ & .76 \\
\hline
\end{tabular}

enhancement on the first contrast enhanced MR imaging sequence. BPE was noticed as minimal-less than $25 \%$ of enhancement ( 8 cases), mild- $25 \%$ to $50 \%$ of enhancement (17 cases), moderate- $50 \%$ to $75 \%$ of enhancement (23 cases) and marked-more than $75 \%$ of enhancement ( 7 cases). MRI morphologic features of MRI detected lesions are summarized in Table 3 and associated findings in Table 4.

Simple fibro adenomas were round or oval in shape (Fig. IA and B) and were showing

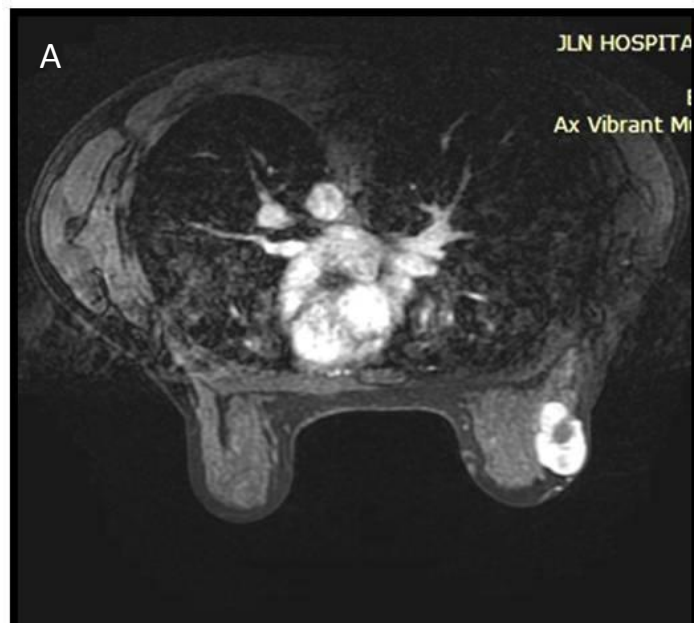




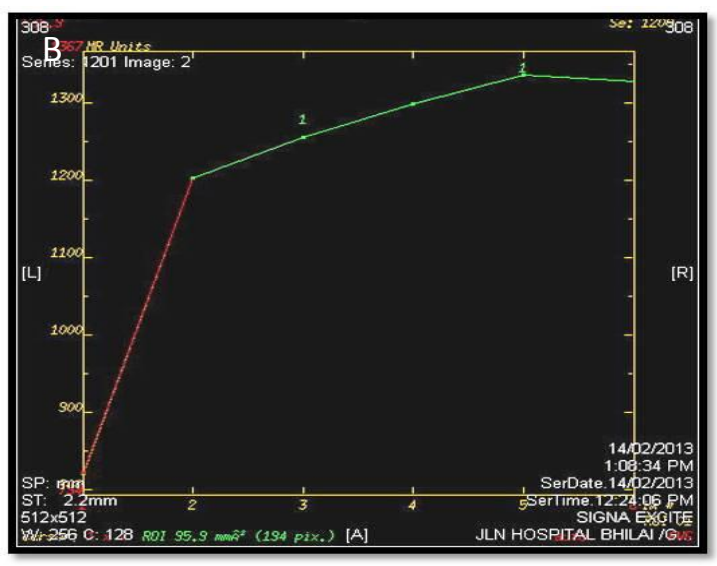

Figure 1A \& B: Fibroadenoma Axial post contrast images showing well circumscribed margin, heterogenous enhancement and type I curve in left breast.

Type I progressive curve. One case of fibro adenoma with micro calcification on mammography showed oval well defined lesion with heterogeneous enhancement and type I benign progressive curve on kinetic enhancement (Fig. 2A and B).
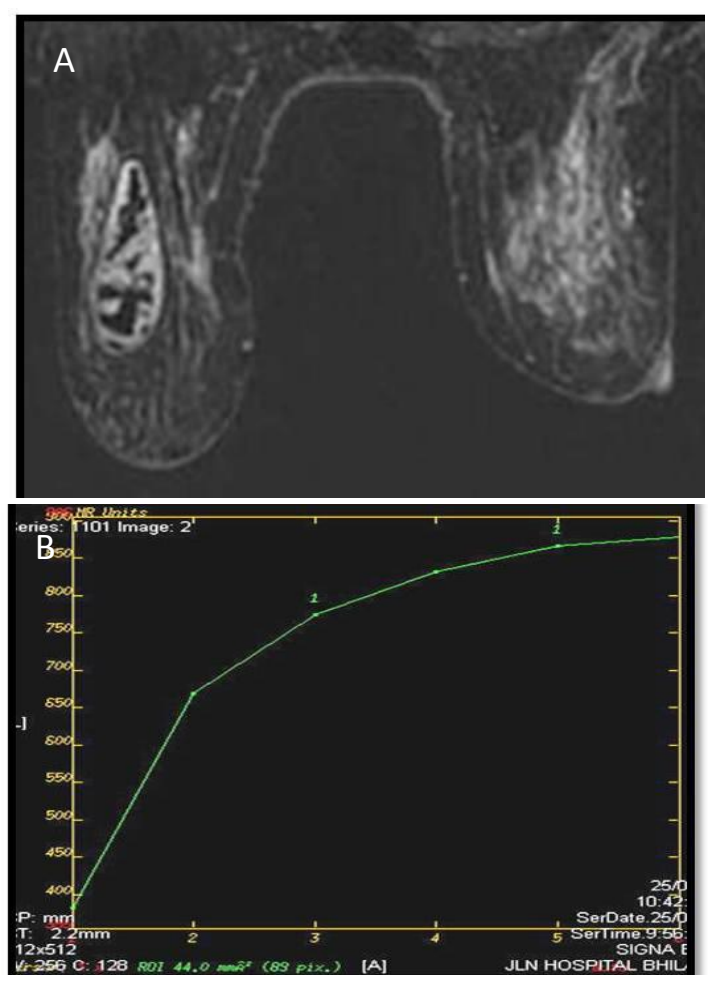

Figure 2A and B: Complicated fibroadenoma, Axial post contrast images demonstrating well circumscribed enhancing oval lesion along with enhancing internal septas and type I curve in left breast.

Table 3: MRI features of MRI Detected Lesions

\begin{tabular}{|c|c|c|}
\hline Features & Benign & Malignant \\
\hline Focus & 4 & \\
\hline Mass & 39 & 27 \\
\hline \multicolumn{3}{|l|}{ Shape } \\
\hline Round & 14 & 2 \\
\hline Oval & 21 & 3 \\
\hline Irregular & 4 & 22 \\
\hline \multicolumn{3}{|l|}{ Margin } \\
\hline Circumscribed & 35 & 3 \\
\hline Irregular, spiculated & 4 & 24 \\
\hline \multicolumn{3}{|l|}{ Internal enhancement } \\
\hline Homogenous & 31 & 2 \\
\hline $\begin{array}{l}\text { Heterogeneous } \\
\text { rim enhancement Dark } \\
\text { internal septation }\end{array}$ & 8 & 25 \\
\hline $\begin{array}{l}\text { Non-mass } \\
\text { enhancement }\end{array}$ & 8 & 2 \\
\hline Focal area & 1 & \\
\hline Linear & 4 & 1 \\
\hline Segmental & 1 & - \\
\hline Regional & - & - \\
\hline Diffuse & 2 & 1 \\
\hline \multicolumn{3}{|l|}{ Internal enhancement } \\
\hline Homogenous & 4 & 1 \\
\hline Heterogenous & 4 & - \\
\hline Clumped & - & 1 \\
\hline Clustered ring & - & \\
\hline \multicolumn{3}{|l|}{ Kinetics } \\
\hline \multicolumn{3}{|l|}{ Initial uptake } \\
\hline Slow & 21 & 3 \\
\hline Medium & 7 & 5 \\
\hline Fast & 4 & 14 \\
\hline \multicolumn{3}{|l|}{ Delayed pattern } \\
\hline Persistent & 26 & 1 \\
\hline Plateau & 6 & 5 \\
\hline Washout & - & 16 \\
\hline
\end{tabular}



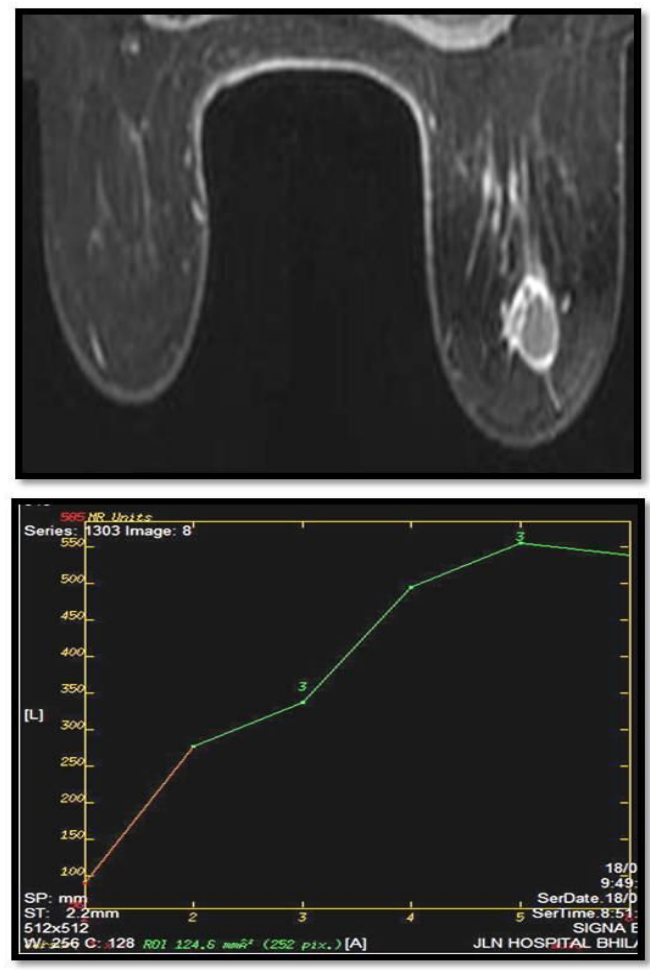

Figure 3A \& B: Fibro cystic disease with ductal cell hyperplasia in right breast and type II curve.
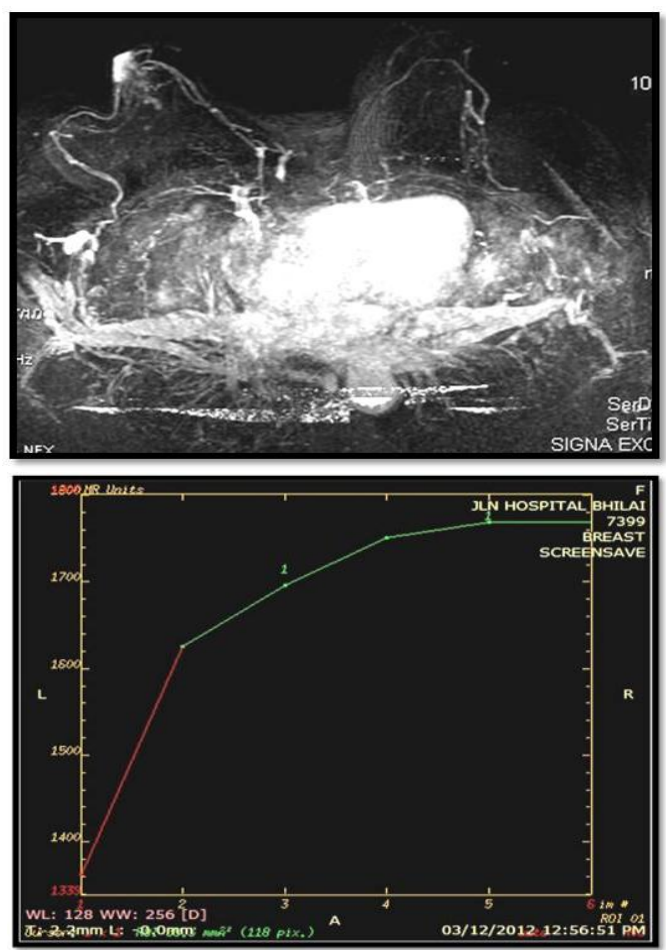

Figure 4 A \& B: Paget's disease of nipple with ductal carcinoma in situ. MIP images showing disc like enhancement of nipple with increase vascularity and type II curve.
A case of fibro cystic disease showed intra cystic projection with areas of increase vascularity. On DEC MRI, peripheral enhancement with few enhancing septas were seen on medial aspect with type II curve, a suspicious lesion, on lumpectomy turned out to be a fibro cystic disease with ductal cell hyperplasia (Fig.3A and B). Three cases of clinically suspicious Paget's disease of nipple were seen, all of them were

\section{Table 4: Associated and other findings.}

\begin{tabular}{|l|l|l|}
\hline $\begin{array}{l}\text { Associated } \\
\text { Findings }\end{array}$ & Benign & Malignant \\
\hline $\begin{array}{l}\text { Skin thickening and } \\
\text { enhancement }\end{array}$ & 2 & 8 \\
\hline Skin retraction & - & 9 \\
\hline Nipple retraction & - & 7 \\
\hline $\begin{array}{l}\text { Subaerolar dilated } \\
\text { ducts }\end{array}$ & 4 & 3 \\
\hline $\begin{array}{l}\text { Lymphadenopathy } \\
\text { Pectoralis muscle } \\
\text { or chest wall } \\
\text { invasion }\end{array}$ & - & 8 \\
\hline $\begin{array}{l}\text { Other findings } \\
\text { Multi focal lesion. }\end{array}$ & 16 & 6 \\
\hline Multi centricity & 9 & 3 \\
\hline $\begin{array}{l}\text { Synchronous } \\
\text { contralateral } \\
\text { lesions }\end{array}$ & 10 & 1 \\
\hline $\begin{array}{l}\text { Contra lateral } \\
\text { lesion }\end{array}$ & 1 & - \\
\hline
\end{tabular}

associated with high grade ductal carcinoma in situ and type II curve (Fig.4A and B), while intra ductal linear subaerolar calcification seen on mammography in one case. Linear enhancing dilated sub aerolar ductal system with two small enhancing lesion within it seen in one case turn out to be high grade ductal carcinoma in situ with intra ductal papilloma ( $5 \times 8 \times 6.7 \mathrm{~mm}$ ) and type II curve (Fig. 5A and B). 

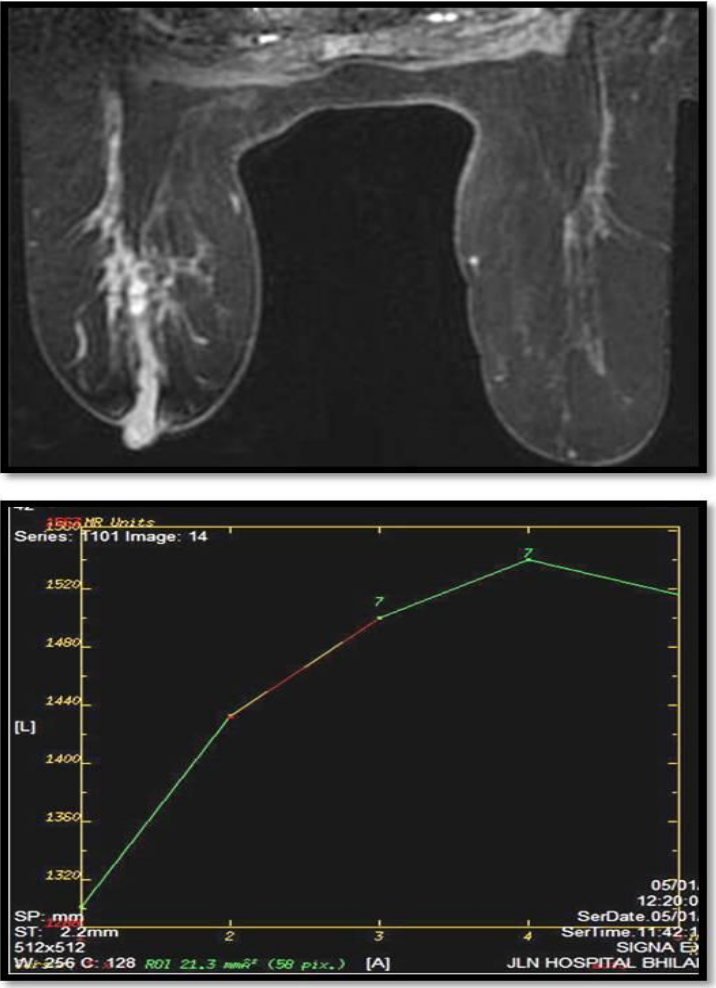

Figure 5A \& B: High grade ductal carcinoma in situ with intra ductal papilloma and type II curve.

Malignant lesions were irregular in shape with irregular or spiculated margins and were showing heterogeneous enhancement with mainly type III curve and associated findings of skin, nipple retraction and lymphadenopathy (Fig.6 and 7A and B). The sensitivity and specificity for diagnosis of malignant lesion was $100 \%$ and $95.65 \%$.

One case of malignant lesion involving both breasts was noticed in 75 year male with no family history of breast cancer (Fig. 8A and B). Breast cancer can occur in unusual sites also. In our study a Fifty three old woman showed irregularly heterogeneous enhancing lesion anterior to left pectoral muscle with normal enhancing intra- mammary lymph node and Type I curve. On the basis of morphology it was diagnose as a malignant lesion and turned out to be high grade ductal carcinoma in situ (Fig.9 A and B). A case of post-operative carcinoma right breast on follow up MRI showed invasive ductal carcinoma in left breast with type II curve (Fig. 10A and B). The pathological findings of MRI Detected lesions are summarized in Table 5. After evaluating lesion morphology and kinetics, they were classified according to MRI BI- RAD Lexicon, Category 1 (6 cases), Category 2(24 cases), Category 3 (7 cases), Category 4 (1case), Category 5 (15 cases) and Category 6 (7 cases).

Table 5: Pathological Findings of MRI detected lesions

\begin{tabular}{|l|l|}
\hline Findings & $\begin{array}{l}\text { No. } \\
\text { Occurrences }\end{array}$ \\
\hline Normal & 6 \\
\hline Benign cases & - \\
\hline Fibrocystic change & 8 \\
\hline Ecstatic changes & 2 \\
\hline Cyst & 3 \\
\hline Fibroadenoma & 12 \\
\hline Ductal Papilloma & 1 \\
\hline Breast abscess & 2 \\
\hline Post-operative scar & 1 \\
\hline Hyperplasia & 1 \\
\hline $\begin{array}{l}\text { Atypical ductal } \\
\text { hyperplasia }\end{array}$ & 2 \\
\hline Malignant cases & 3 \\
\hline $\begin{array}{l}\text { Paget's Disease with } \\
\text { ductal carcinoma }\end{array}$ & 3 \\
\hline Ductal carcinoma in situ & 7 \\
\hline $\begin{array}{l}\text { Infiltrating ductal } \\
\text { carcinoma }\end{array}$ & 8 \\
\hline $\begin{array}{l}\text { Infiltrating lobular } \\
\text { carcinoma }\end{array}$ & 3 \\
\hline Medullary carcinoma & 1 \\
\hline
\end{tabular}



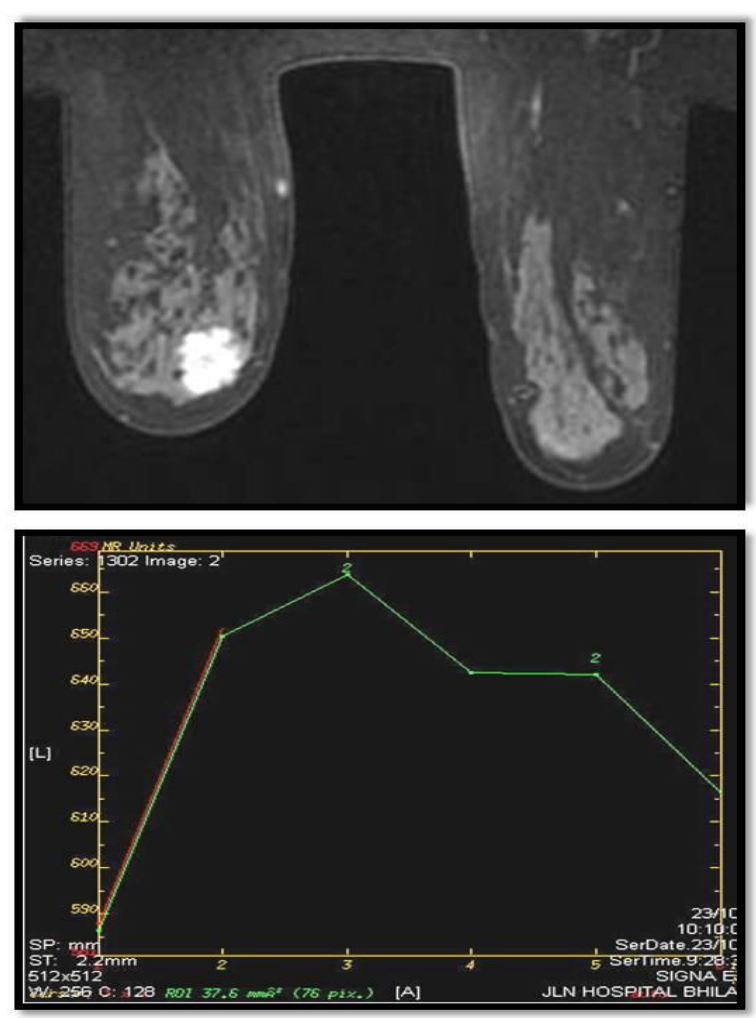

Figure 6A and B: Invasive ductal carcinoma with type III curve in right breast.

Diffusion weighted imaging at $b$ value of 500 was carried out in all sixty cases. Normal ADC of breast parenchyma was between $1.2-1.79 \times 10^{-3} \mathrm{~mm}$. For malignant lesion (18 cases), decrease ADC value 1.03$1.14 \times 10^{-3} \mathrm{~mm}$ were seen as compare to benign lesions (25 cases), of ADC value $1.80-2.53 \times 10^{-3} \mathrm{~mm}$.

\section{Discussion}

Dynamic contrast enhanced MRI is useful for characterization of breast lesions and additional information derived from kinetic curve type to architectural features of a lesion improves the specificity of MRI. Fibrocystic changes (FCC) of the breast are a benign breast disease affecting more than $50 \%$ of women. FCC with epithelial proliferation has been associated with an
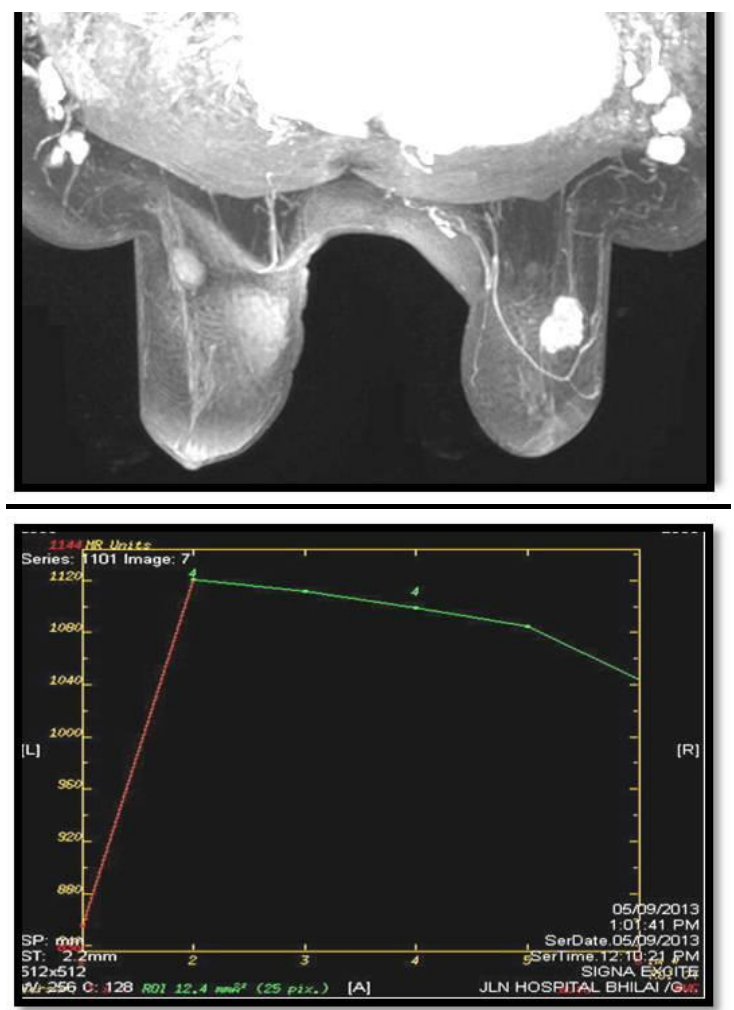

Figure 7A \& B: MIP images showing infiltrating ductal carcinoma left breast with metastatic lymphadenopathy and type III curve.

increased risk of subsequent breast cancer especially if accompanied with atypical cellular changes. MRI helps to exclude breast Cancer and premalignant lesions in FCC patients and facilitate to decrease unnecessary biopsy rate for an actually benign condition ${ }^{5,6}$. In our study most of the patients showed single or multiple foci of benign enhancement and two patients showed non mass enhancement. Most of the patients showed type I curve whereas type II curve was noticed in one patient associated with ductal cell hyperplasia.

Fibroadenomas are the most common benign tumor in young women, with increasing age water content of these tumor decreases and fibrotic component increases. ${ }^{7,8}$ They were mainly seen as round or oval lesions with homogenous enhancement and type I curve. 

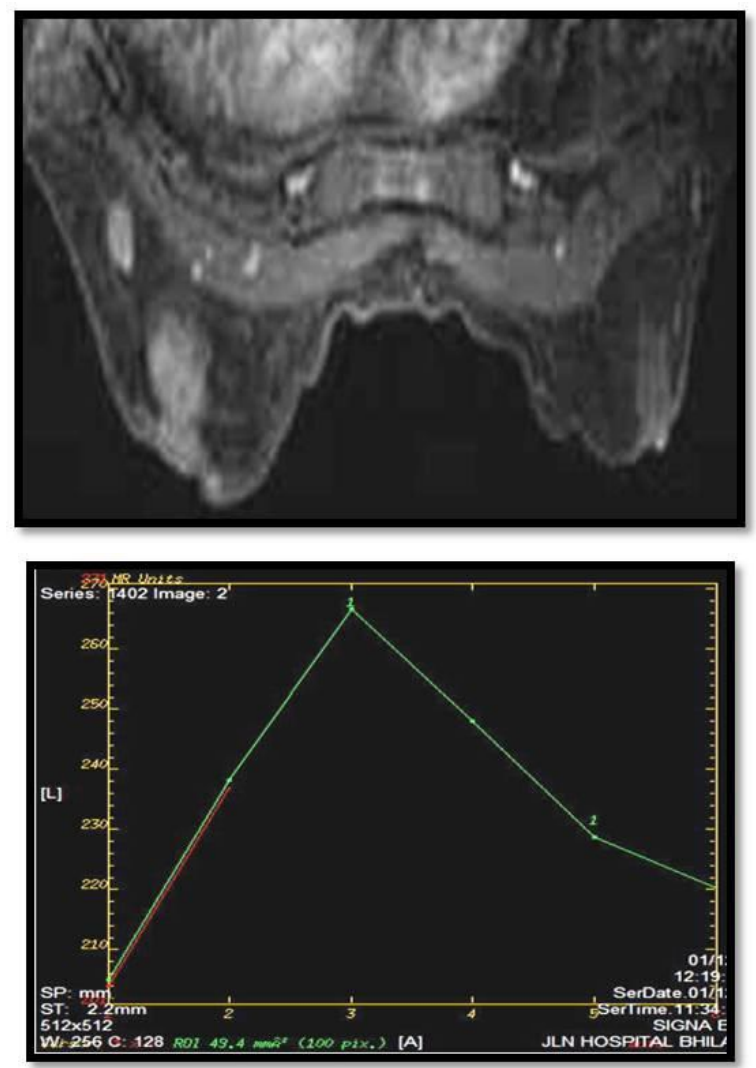

Figure 8A \& B: Invasive ductal carcinoma in male both breast with type III curve.

Six of our cases were showing heterogeneous enhancement with well define margin and type II curve.

In our study we saw seven cases of ductal carcinoma in situ (DCIS), out of that two were seen as nonmass enhancing lesion. All mass like lesion were Irregular in shape and curve predominantly showing plateau (6 cases) followed be persistent kinetic curve in one case. These finding were concordant with those in previous study performed by Jeong Ahkin and et al. ${ }^{9}$ Tumor angiogenesis is a critical factor in breast tumor growth and aggressiveness. Neovascularizations of pure DCIS lesions result in early rapid contrast uptake and that tumor angiogenesis and structural abnormality of vessels in pure DCIS lesions are more prominent than in benign lesions but less prominent than in invasive malignant tumor. ${ }^{10,11}$
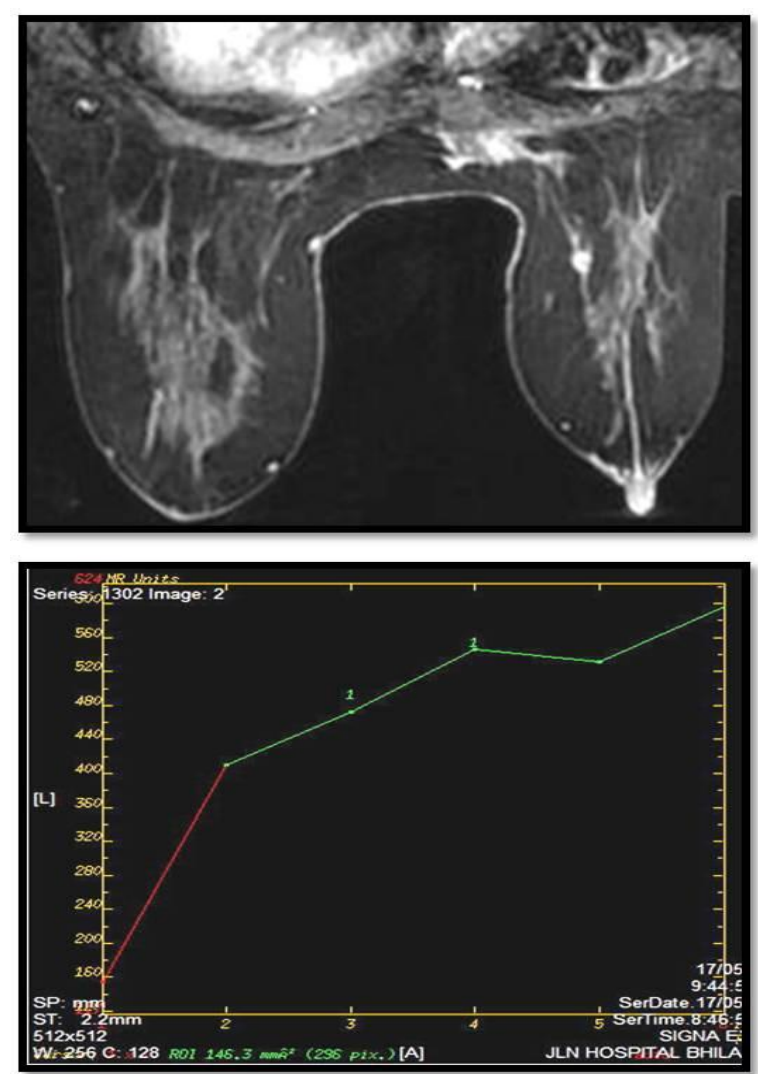

Figure 9A \& B: High grade ductal carcinoma in situ anterior to right pectoral muscle with normal intra mammary lymph node in right breast and a type I curve.

Invasive ductal carcinoma is the most common primary malignant tumors of the breast. MRI demonstrated an irregular shaped, spiculated mass with rim or heterogeneous enhancement with mostly type II or type III curve. ${ }^{12}$ Our study also showed similar findings reported by Gurpreet S. Dhillon. ${ }^{13}$ We saw seven cases of invasive ductal carcinoma with type III curve.

Medullary carcinoma of the breast is a rare invasive breast malignancy and accounts for fewer than $5 \%$ of breast carcinomas. ${ }^{14}$ One case of medullary carcinoma with type III curve was seen in our study. Paget's disease of the breast consists of the infiltration of the nipple areolar complex epidermis by 
adenocarcinoma cells and accounts for approximately $2 \%$ or $3 \%$ of breast carcinoma and is often associated with underlying ductal carcinoma in situ, which may also have an infiltrating component.
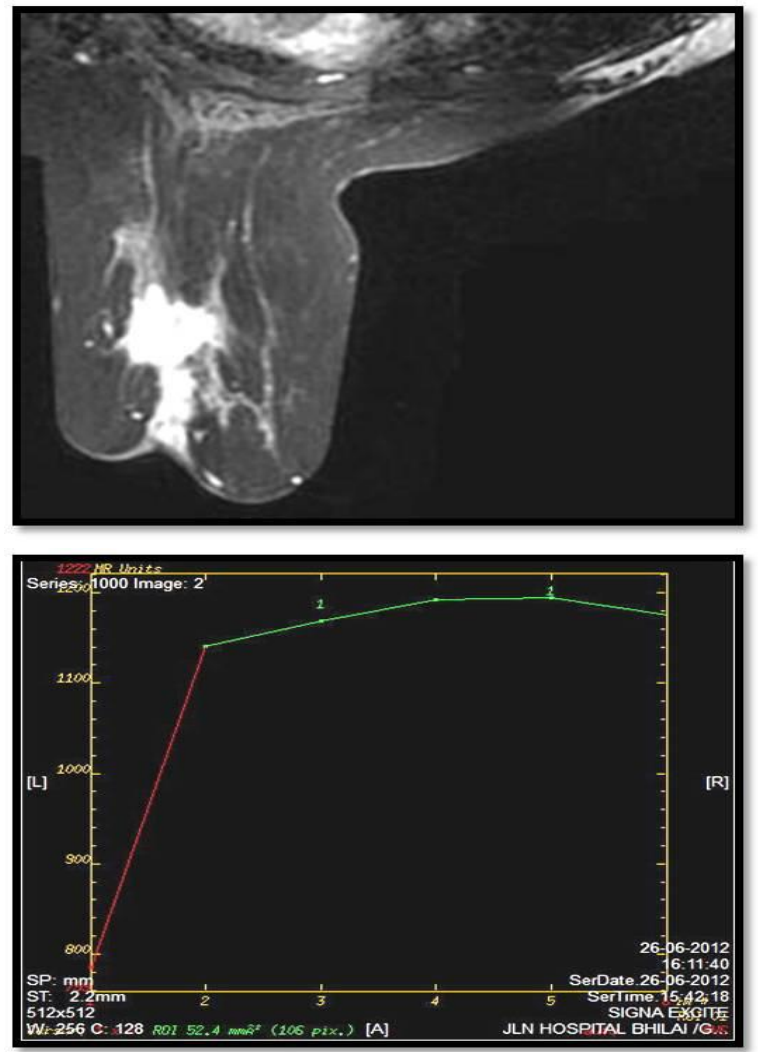

Figure 10A \& B: Post-operative case of carcinoma right breast, now invasive ductal carcinoma in left breast with type II curve.

MRI allows detection of mammographically and clinically occults breast neoplasms in patients with Paget's diseases. Three cases of Paget's disease associated with ductal carcinoma in situ were seen in our study and all off them showed type II curve as compare to type II type I curve noticed in the study of J. J. Eihevarria and et al. ${ }^{15}$

Diffusion Weighted imaging (DWI) is used to improve the specificity of MRI for the evaluation of breast lesions. By using the DWI sequences, one can calculate the apparent diffusion coefficient (ADC), a quantitative measure that is directly proportional to the water diffusion. High cell proliferation in malignant tumors increases cellular density, creating more barriers to the extra cellular water diffusion, reducing the ADC, and resulting in signal loss. This sequence appears to be a useful tool for tumor detection and characterization as well as monitoring and predicting treatment response. $^{16,17}$ In our study the mean ADC obtained from malignant breast lesions was significantdly lower than that observed in benign lesions.

\section{Conclusion}

By evaluating the morphology and kinetic features of different breast lesions in our study the following guide lines have emerged which is demonstrated in a flow chart no I .

1. If morphology suggests a benign lesion with type I time course than it support the diagnosis of a benign lesion and may be used to preclude the performance of biopsy.

2. If morphology suggests a probably benign or indeterminate lesion, but a plateau or washout time curve is detected, biopsy must be performed on the lesion. A washout constitute an absolute indication to perform biopsy irrespective of other MR criteria particularly morphology.

3. If morphology suggests a malignant lesion then kinetic does not have much role, it can only help to confirm the presence of breast cancer with washout kinetics. Type I signal intensity curve 


\section{Chart I: Flow chart showing management of MRI detected lesions.}

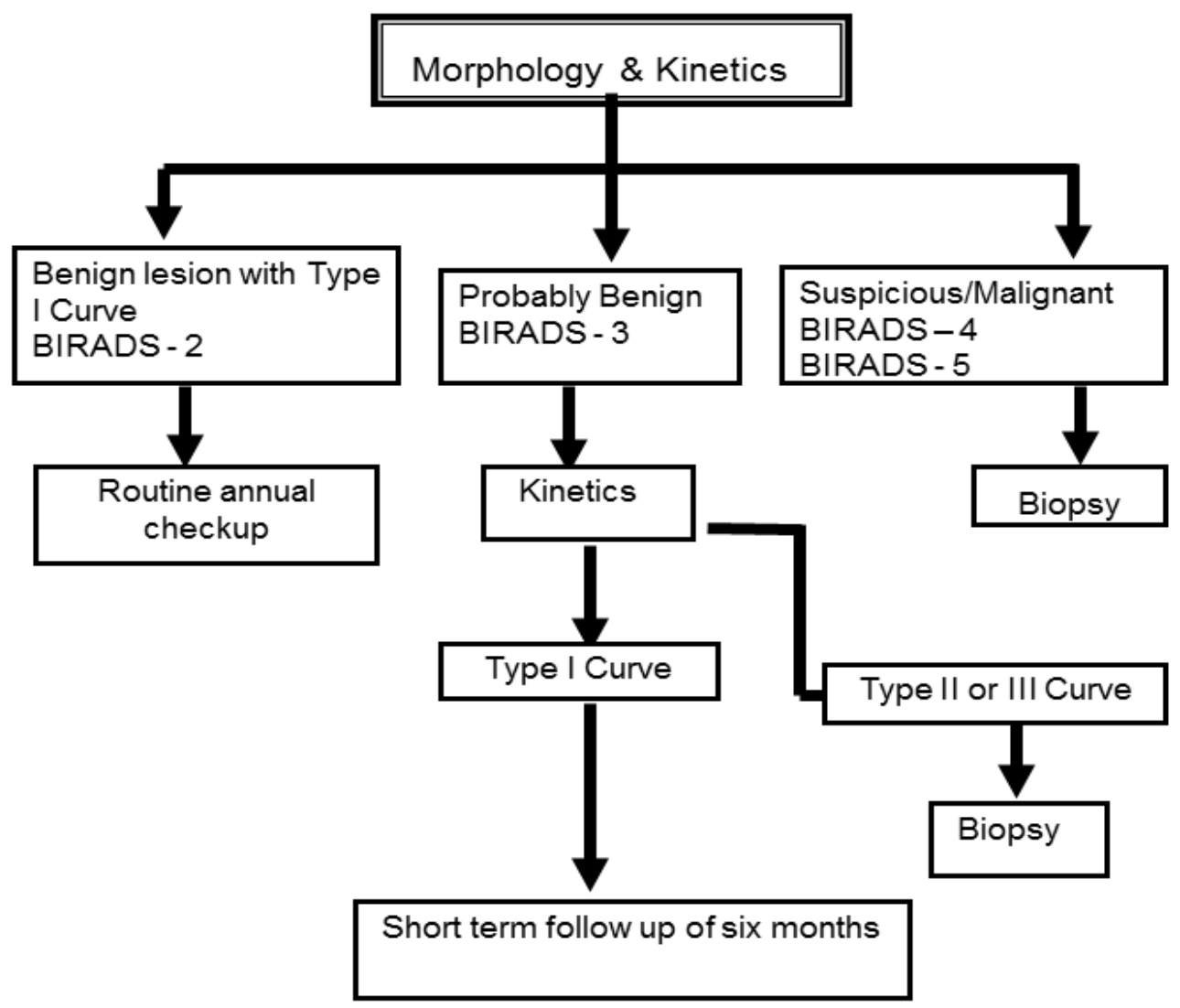

may not be used to preclude the performance of biopsy, because the lesion may represent lobular, scirrhous or ductal carcinoma in situ.

\section{Reference}

1. Morris EA, Schwartz LH, Dershaw DD, Van Zee KJ, Abramson AF, Liberman L . MR imaging of the breast in patient with occult primary breast carcinoma. Radiology 1997;205:437440.

2. Oral SG, Schnall MD, MR imaging of the breast for the detection, diagnosis and staging of breast cancer Radiology 2001;220:13-30.

3. Sona D. Edevards Jafi A Lipson, Debra M I Keda Janie M Lee. Update and
Revision to the BI-RADS magnetic Resonance Imaging lexicon. Magnetic Resonance Imaging clinics of North America 21 (2013) 483-493.

4. Gutrierrez RL, De Martini WB, Eby PR, et al. BIRADS lesion characteristics predict likehood of malignancy in breast MRI for masses but not for no mass like enhancement. AJR 2009, 193: 994-1000.

5. Chen JH, Nalciogluo su M. Fibrocysitc changes of the breast presenting as a focal lesion mimicking breast cancer in MR Imaging $\mathrm{J}$ magn Reson imaging 2008; 25:1499-1505.

6. Chen $\mathrm{CH}$, liu H Back HM, Nalcioglu O, $\mathrm{Su} \mathrm{My}$. Magnetic resonance imaging features of fibro cystic changes of the 
breast Magn. Reson.imaging 2008; 26:1207-1214.

7. Kuhl $\mathrm{C} \mathrm{K}$ The current status of breast MR imaging part I choice of technique, image interpretation, diagnostic accuracy and transfer to clinical practice. Radiology 2007; 244(2):356-78.

8. Kuhl C K. Current status of breast MR imaging part 2 clinical applications. Radiology 2007; 244(3):672-91.

9. Jeong-Ah Kim, Eu Ju Son, Ji Hyun Youk etall. MRI Findings of pure ductal carcinoma in situ: Kinetic Characteristics compared according to lesion type and Histopathologic factors AJR 2011; 196:1450-1456.

10. Knopp M.V Weiss E, Sum HO et al. Patho physiologic basis of contrast enhancement in breast tumors, J Magn Reson Imaging 1999, 10(3): 260-6.

11. Raza S Vallejo M, Chikarmane SA etal. Pure ductal carcinoma in situ. A range of MRI feature AJR 2008; 191:689-99.

12. Orel SG, Schnall MD. MR imaging of the breast for the detection, diagnosis and staging of breast cancer Radiology 2001:220:13-30.

13. Gurpeet S Dhillon, Nick Bell, Daniel T. Ginat, Alena Levit, Stamatia Destounis, Avice O' Connell. Breast MR Imaging: What the radiologist needs to know. Journal of Clinical Imaging Science 2011; $1: 48$.

14. Su Jin Jeong, Hyo Soon Lin, Ji Shin Lee and etall. Medullary carcinoma of the breast: MRI Findings. AJR 2012;198:482-487.

15. J J Echevarria, J. A Lopez Ruiz, D Martin, I Imaz and M Martin.Usefulness of MRI in detecting occult breast cancer associated with Paget's disease of nippleareolar complex. British Journal of Radiology December 1, 2004 vol,77 no 924,1036-1039.

16. Rubevova E, Grell AS, Dc Maertelaer V, Metend $\mathrm{T}$, Chao SL, Lemort $\mathrm{M}$. Quantitative diffusion imaging in breast cancer. A clinical prospective study. J magn Reson imaging 2006, 24: 319-324.

17. Paran Y, Bendel P, Margalit R, Degani $\mathrm{H}$, Water diffusion in the different microenvironment of breast cancer. NMR Biomed 2004; 17:170-180. 